\title{
Mechanobiology of the meniscus
}

\author{
Amy L. McNulty*, Farshid Guilak \\ Department of Orthopaedic Surgery, Duke University Medical Center, Durham, NC 27710, United States
}

\section{A R T I C L E I N F O}

\section{Article history:}

Accepted 3 February 2015

\section{Keywords:}

Mechanical signal transduction

Articular cartilage

Collagen

Fibrochondrocyte

Proteoglycan

\begin{abstract}
A B S T R A C T
The meniscus plays a critical biomechanical role in the knee, providing load support, joint stability, and congruity. Importantly, growing evidence indicates that the mechanobiologic response of meniscal cells plays a critical role in the physiologic, pathologic, and repair responses of the meniscus. Here we review experimental and theoretical studies that have begun to directly measure the biomechanical effects of joint loading on the meniscus under physiologic and pathologic conditions, showing that the menisci are exposed to high contact stresses, resulting in a complex and nonuniform stress-strain environment within the tissue. By combining microscale measurements of the mechanical properties of meniscal cells and their pericellular and extracellular matrix regions, theoretical and experimental models indicate that the cells in the meniscus are exposed to a complex and inhomogeneous environment of stress, strain, fluid pressure, fluid flow, and a variety of physicochemical factors. Studies across a range of culture systems from isolated cells to tissues have revealed that the biological response of meniscal cells is directly influenced by physical factors, such as tension, compression, and hydrostatic pressure. In addition, these studies have provided new insights into the mechanotransduction mechanisms by which physical signals are converted into metabolic or pro/antiinflammatory responses. Taken together, these in vivo and in vitro studies show that mechanical factors play an important role in the health, degeneration, and regeneration of the meniscus. A more thorough understanding of the mechanobiologic responses of the meniscus will hopefully lead to therapeutic approaches to prevent degeneration and enhance repair of the meniscus.
\end{abstract}

(c) 2015 Elsevier Ltd. All rights reserved.

\section{Introduction}

The menisci are fibrocartilaginous tissues that play a critical role for the transmission and distribution of loads in the knee (Walker and Erkman, 1975). The unique properties of the menisci are determined by the complex geometry, ultrastructure, and composition of the tissue, which consists of a hydrated extracellular matrix composed largely of collagen, which varies in type from predominantly type II collagen in the more cartilaginous inner zone, to primarily type I collagen in the vascularized, fibrous outer zone (Fithian et al., 1990; Makris et al., 2011). The remainder of the solid matrix includes smaller amounts of other collagens, proteoglycans, proteins, and glycoproteins (McDevitt and Webber, 1990). Injury or degeneration of the meniscus is associated with pain and joint dysfunction, and loss of meniscal function or surgical meniscectomy leads to relatively rapid and progressive osteoarthritis (Fairbank, 1948). Partial meniscectomy is often utilized to treat meniscal tears; however, despite improvements in pain and function, this surgery does not protect against the development of osteoarthritis (Andersson-Molina et al., 2002; Hall et al., 2014; Hoser et al., 2001). In addition, the menisci show little capacity for repair, except for certain types of injuries occurring in the

\footnotetext{
* Corresponding author. Tel.: +1 919684 6882; fax: +1 9196818490.

E-mail address: alr@duke.edu (A.L. McNulty).
}

peripheral vascularized region (Arnoczky and Warren, 1983; Scott et al., 1986).

The composition and structure of the meniscus are maintained through a balance of the anabolic and catabolic activities of the residing cells, often termed "fibrochondrocytes." The biological activity of meniscal cells is controlled not only by genetic and biochemical factors, such as growth factors and cytokines (Collier and Ghosh, 1995; McNulty et al., 2013; Pangborn and Athanasiou, 2005; Riera et al., 2011), but also by physical factors associated with joint loading. It is now clear that mechanical factors play a critical role in the development, maintenance, degeneration, and repair of the meniscus. In this regard, a thorough understanding of the mechanobiology of the meniscus under physiologic and pathologic loading conditions may provide important insights into the prevention and treatment of meniscal injuries and degeneration.

A range of different approaches has been used to study the mechanobiologic responses of the meniscus, ranging from in vivo studies to the cell and molecular level, with each type of study providing certain advantages and disadvantages. In vivo animal studies generally represent the most physiologically relevant model systems and can provide a means for studying long-term (i.e., weeks to years) effects associated with development, remodeling, or repair. In vivo studies are generally limited by the complexities involved in determining the precise mechanical environment of the menisci, and may be further complicated by the effect of systemic 
factors. At the tissue level, in vitro studies can provide important information on the mechanobiologic regulation of meniscal cells, where both applied load and biochemical environment can be better controlled. These studies have generally focused on meniscal explants or isolated cells grown in three-dimensional (3D) matrices. In explant culture, the native cell-matrix interactions are maintained; however, in cartilaginous tissues, the presence of the extracellular matrix generates other physical signals associated with applied loading that can vary significantly with time and at different sites in the tissue. Thus, many of the biophysical phenomena that may be directly responsible for regulating meniscal cell responses cannot be uncoupled in a tissue explant model. Thus, studies on isolated cells can provide model systems for studying specific signal transduction pathways or for isolating the effects of a single biophysical stimulus, such as stretch or hydrostatic pressure.

In this paper, we present a review of the mechanobiology of the meniscus - that is, the influence of mechanical factors on the biological response of meniscal cells. These studies have been performed in a range of model systems across different geometric scales and the interpretation of these studies has been greatly enhanced by the use of theoretical and experimental models designed to predict and quantify the mechanical environment of cells in the meniscus under different loading conditions. Furthermore, several in vivo and in vitro studies have begun to examine the influence of mechanical factors on meniscal regeneration and repair. Together, these studies further enhance our understanding of the role of mechanobiology in the development, growth, maintenance, degeneration, and repair of the meniscus.

\section{In vivo studies of meniscal mechanobiology}

In the 19th century, it was generally believed that the menisci were inert vestigial tissues that were remnants of intra-articular muscles (Bland-Sutton, 1897). However, classical studies by Fairbank (1948) and numerous more recent studies (Roos et al., 2001) have shown distinct and repeatable deleterious changes in the knee joint following loss of the meniscus. It is now apparent that not only is the meniscus a critical functional element of the knee joint, it also contains multiple subpopulations of active cells that are responsible for tissue development, maintenance, and repair (Hellio Le Graverand et al., 2001; Verdonk et al., 2005). The specific morphology and arrangement of the meniscal cells may play a role in their ability to respond to different types of mechanical signals experienced throughout the tissue. Importantly, growing evidence has shown that these cells are highly responsive to the local biophysical environment under both physiologic and pathologic conditions, and that changes in the loading history of the joint can alter meniscal composition, structure, and inflammatory response.

Much of the initial data on the mechanosensitivity of the meniscus came from in vivo studies of joint immobilization. Immobilization was found to lead to a "disuse atrophy" that was characterized by the loss of proteoglycans in the meniscus (Klein et al., 1982; Videman et al., 1979). These changes are apparent histologically, as well as at the gene expression level (Djurasovic et al., 1998) and are also reflected in altered mechanical properties and function of the meniscus (Anderson et al., 1993; Ochi et al., 1997). Further evidence for the mechanosensitive behavior of the meniscal cells was shown by the fact that loss of the extracellular matrix components can be prevented through muscular stimulation in cast-immobilized joints (Burr et al., 1984) or through active motion without direct weight-bearing (Klein et al., 1989). Interestingly, limb immobilization in the chick embryo prevented the formation of the meniscus, indicating the critical role of mechanobiology in meniscal development (Mikic et al., 2000). Furthermore, exercise has been shown to alter the composition of the meniscus. For example, treadmill run- ning caused a significant decrease in dermatan sulfate proteoglycans, as well as the number of pyridinoline crosslinks per mole of collagen in the menisci of chickens (Pedrini-Mille et al., 1988). These effects were age-dependent, and only occurred during the period of active growth. In rats, strenuous treadmill running was found to cause changes in the hydroxyproline and calcium contents of the lateral meniscus, but only in the posterior region (Vailas et al., 1986).

Consequently, it is not surprising that mechanical factors can influence meniscal repair in vivo. For example, in a dog model, lesions in the vascular region of the medial meniscus exhibited decreased collagen content in animals that were cast immobilized, as compared to animals that were mobilized immediately after surgery (Dowdy et al., 1995). While the mechanisms involved in this response are not well understood, other studies in a rabbit model showed that injury to the medial meniscus was characterized by a five-fold increase in blood flow to the menisci 4 weeks post-operatively. However, immobilization of the knee joint prevented this increase (Bray et al., 2001). Furthermore, in vivo studies have shown that mechanical loading can drive either anti-inflammatory or pro-inflammatory responses of meniscal cells. In a rabbit model of antigen-induced arthritis, continuous passive motion was found to prevent proteoglycan degradation and loss from the meniscus, as compared to immobilized knees (Ferretti et al., 2005). Interestingly, continuous passive motion induced an anti-inflammatory response, characterized by increased levels of the cytokine interleukin (IL)-10 in meniscal fibrochondrocytes. Conversely, injurious joint loading in a tibiofemoral impaction model in the rabbit has been shown to result in a significant decrease in cell viability in the lateral menisci following injury, and a trend towards increased pro-inflammatory mediators, such as nitric oxide (NO) (Killian et al., 2014). Taken together, these in vivo studies emphasize the importance of physiologic mechanical loading in the health and function of the meniscus and consequently the entire knee joint, and indicate that abnormal loading can result in catabolic and proinflammatory responses by meniscal cells.

\section{Mechanical environment at the tissue and cellular level}

From these in vivo studies, it is apparent that the mechanical loading history of the knee has a strong influence on the metabolic activity of cells within the meniscus. However, the precise mechanisms involved in regulating the synthesis and breakdown of meniscal matrix components are not fully understood. A critical factor in deciphering the mechanisms of meniscal cell response to joint loading is an understanding of the stress-strain environment of the meniscus and surrounding tissues under physiologic or pathologic loading conditions. However, due to the inhomogeneous composition and the anisotropic structure and mechanical properties of the meniscus, the local stress-strain and fluid flow environments may vary greatly with time and location. Furthermore, the charged and hydrated properties of the tissue result in complex physicochemical, electrical, and fluid flow environments, in addition to tensile, compressive, and shear stresses and strains. Thus, it has been difficult to isolate the effects of specific biophysical factors on meniscal cell activity due to the intrinsic coupling of these various phenomena.

Thus, to better understand the biophysical environment of the meniscus, a number of studies have used minimally-invasive imaging modalities, such as magnetic resonance imaging (MRI) or roentgen stereophotogrammetric analysis (RSA) to measure meniscal deformation in situ. In human knees, both lateral and medial menisci were found to undergo large movements, as well as morphologic changes, during knee joint flexion (Kawahara et al., 1999; Tienen et al., 2005; Vedi et al., 1999). Furthermore, following running, menisci showed a significant loss of volume that was dependent on the duration of exercise (Kessler et al., 2006), and both T1rho and T2 MR signal intensities were found to increase after a 

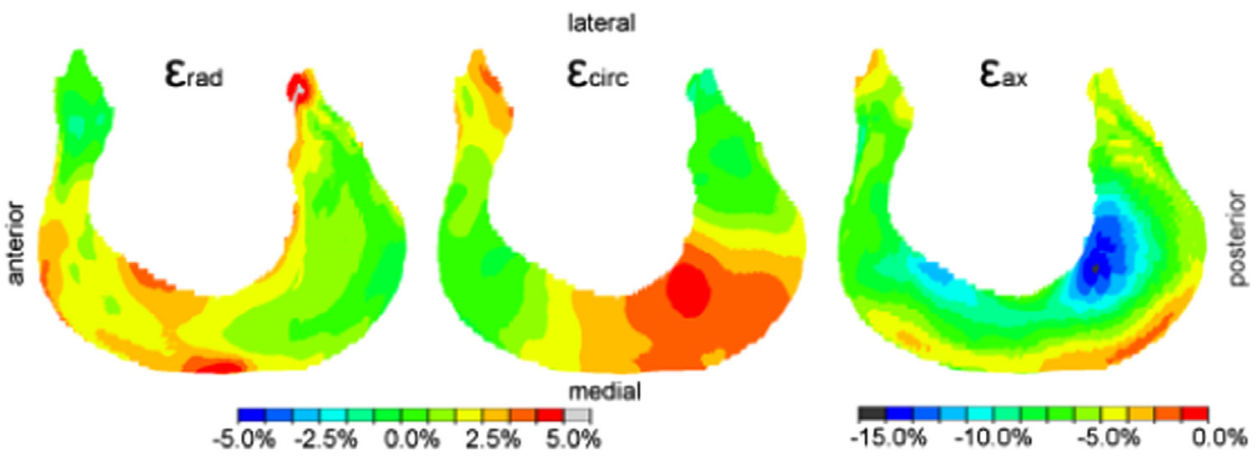

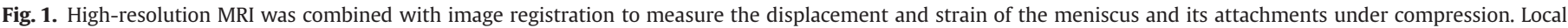

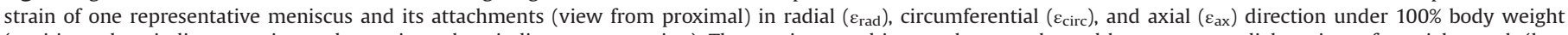

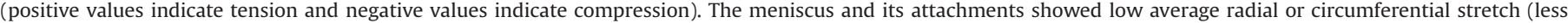
than 1\%), but axial strains of nearly $12 \%$ during physiologically relevant loading of the knee. Reprinted with permission from Freutel et al. (2014).

marathon, indicative of persistent matrix changes (Stehling et al., 2011). More recently, volume registration of MR images was used to examine 3D displacement and local strain in the meniscus of pig knees. This study found that the meniscus and its attachments showed low average radial or circumferential stretch (less than 1\%), but axial strains of nearly $12 \%$ during physiologically relevant loading of the knee (Fig. 1) (Freutel et al., 2014).

To determine the internal stress-strain and fluid pressure environment, computational methods such as finite element modeling are necessary in combination with appropriate constitutive and geometric representations of the meniscus. Such models have provided important insights on the mechanical environment of the meniscus under different loading conditions and have shown that the predicted stress and strain fields were highly dependent on the assumed mechanical properties of the tissue, and thus could exhibit significant inhomogeneity and anisotropy (Meakin et al., 2003; Spilker et al., 1992; Yao et al., 2006). The incorporation of fluid pressurization effects through a biphasic or poroelastic model was found to be necessary to account for the physiologic load-bearing capacity of the meniscus (LeRoux and Setton, 2002; Spilker et al., 1992). Furthermore, damage or partial loss of the meniscus or knee ligaments can greatly influence the displacement and deformation of the meniscus under load (Yao et al., 2006). Importantly, the predictions of such models have been confirmed or validated directly using MRI and pressure sensor measurements (Bedi et al., 2010; Halonen et al., 2014).

To better understand the mechanobiologic response of meniscal cells, several studies have developed novel computational or experimental systems to predict or measure the relationship between the macroscale mechanical environment of the meniscus and the local microscale environment around individual cells. At the tissue level, the meniscus has been shown to possess distinct depth-dependent strain profiles during compression (Lai and Levenston, 2010) and the transfer of strains to the local level has been shown to exhibit considerable spatial heterogeneity, with evidence of both strain amplification and attenuation, depending on the site within the meniscus (Han et al., 2013; Upton et al., 2008). These characteristics are consistent with a complex mechanical environment that may arise from fiber sliding, fiber twisting, and fiber-matrix interactions that are present in the meniscus.

While such experimental studies and standard finite element models of meniscus mechanics have provided important information on the spatial and temporal stress-strain environment at the microscale tissue level, the mechanical environment at the cellular level will depend on other factors, including the structure and mechanical properties of the pericellular matrix, as well as those of individual cells (Guilak and Mow, 2000). In the past decade, several studies have begun to report such properties and their application in finite element models of cell-matrix interactions in the meniscus. The first measure of meniscal cell mechanical properties was performed using micropipette aspiration of isolated cells, which showed a mean instantaneous Young's modulus of $\sim 0.5 \mathrm{kPa}$ and an equilibrium modulus of $\sim 0.2 \mathrm{kPa}$ (Upton et al., 2006a). In other studies, bulk cell compression was used to measure the properties of meniscal cells, showing that they can differ significantly between inner and outer zone cells (SanchezAdams and Athanasiou, 2012). By incorporating such cell mechanical properties, along with meniscal cell geometries, into a nonlinear anisotropic biphasic model, finite element studies have begun to examine the relationship between extracellular matrix strain and cell strain, showing significant regional differences in the cellular mechanical environment in response to biaxial tissue strains (Fig. 2) (Upton et al., 2006a). In other studies, a 2D, non-linear, fiber reinforced, multiscale finite element model was utilized to quantify changes in the stress, strain, fluid velocity and fluid flow induced shear stress in the vicinity of meniscal cells (Gupta and Haut Donahue, 2006). This study showed that not only did cell shape and location significantly influence the mechanical environment, but that the pericellular matrix could play a significant role in shielding the cell from large principal strains and stresses. While the presence of a pericellular region had been observed previously in the meniscus (McDevitt et al., 2001), only recently have the microscale properties of this region been investigated. By combining atomic force microscopy (AFM) with simultaneous fluorescence imaging of perlecan to demarcate the pericellular matrix, the mechanical properties of matched pericellular and extracellular matrix sites were spatially mapped within the outer, middle, and inner porcine medial meniscus (Sanchez-Adams et al., 2013). This study showed that the elastic modulus of the meniscus pericellular matrix was significantly higher in the outer region $(\sim 150 \mathrm{kPa})$ than the inner region ( $\sim 28 \mathrm{kPa}$ ) (Fig. 3), whereas extracellular matrix moduli were consistently higher than region-matched pericellular matrices in both outer $(\sim 321 \mathrm{kPa})$ and inner $(\sim 66 \mathrm{kPa})$ regions. These findings indicate that the structure and composition of the tissue can regulate the local stress-strain environment of meniscal cells among the different regions of the tissue (Sanchez-Adams et al., 2013).

\section{Explant and 3D studies of meniscal mechanobiology}

The effects of controlled mechanical loading regimes have been assessed on tissue explants, which maintain the meniscal cells in the context of the native extracellular matrix. Mechanical loading effects on meniscal explants depend on the strain and magnitude of the applied load, the frequency, and the type of load applied. In general, dynamic compression tends to be anabolic at $10 \%$ strain but then the balance shifts towards catabolism at 20\% strain (Gupta et al., 2008; Zielinska et al., 2009). In particular, the physiologic strain of $10 \%$ for $2 \mathrm{~h}$ at $1 \mathrm{~Hz}$ suppressed the release of the pro-inflammatory mediator 

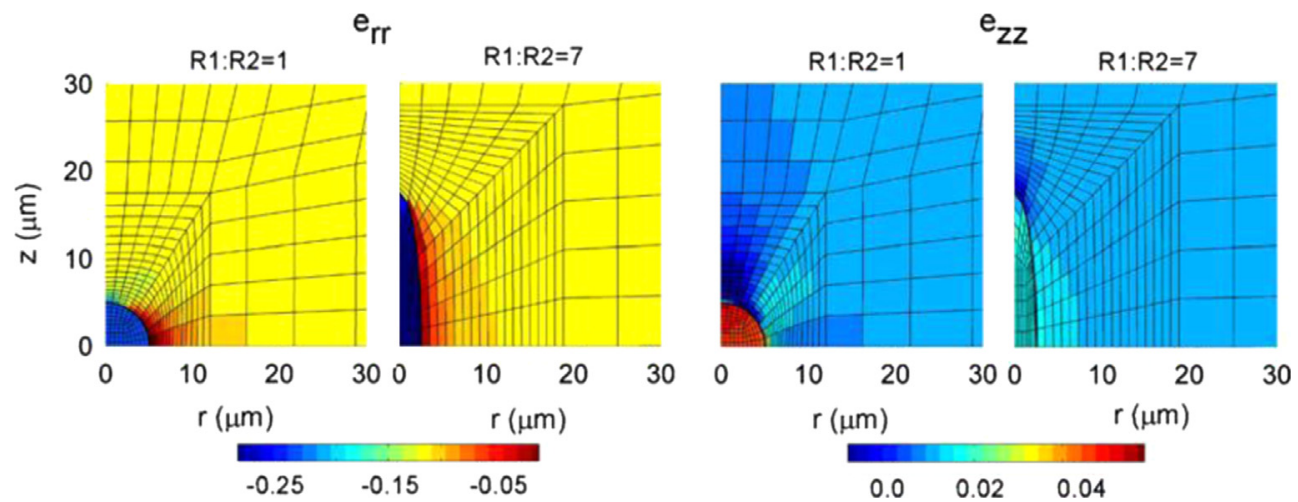

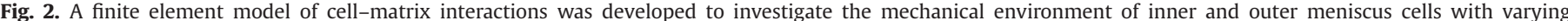

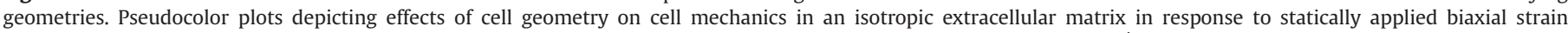

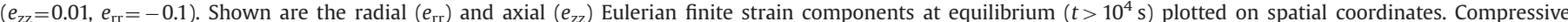

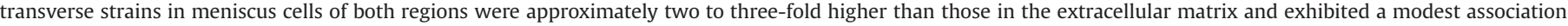
with cell aspect ratio. Reprinted with permission from Upton et al. (2006a).
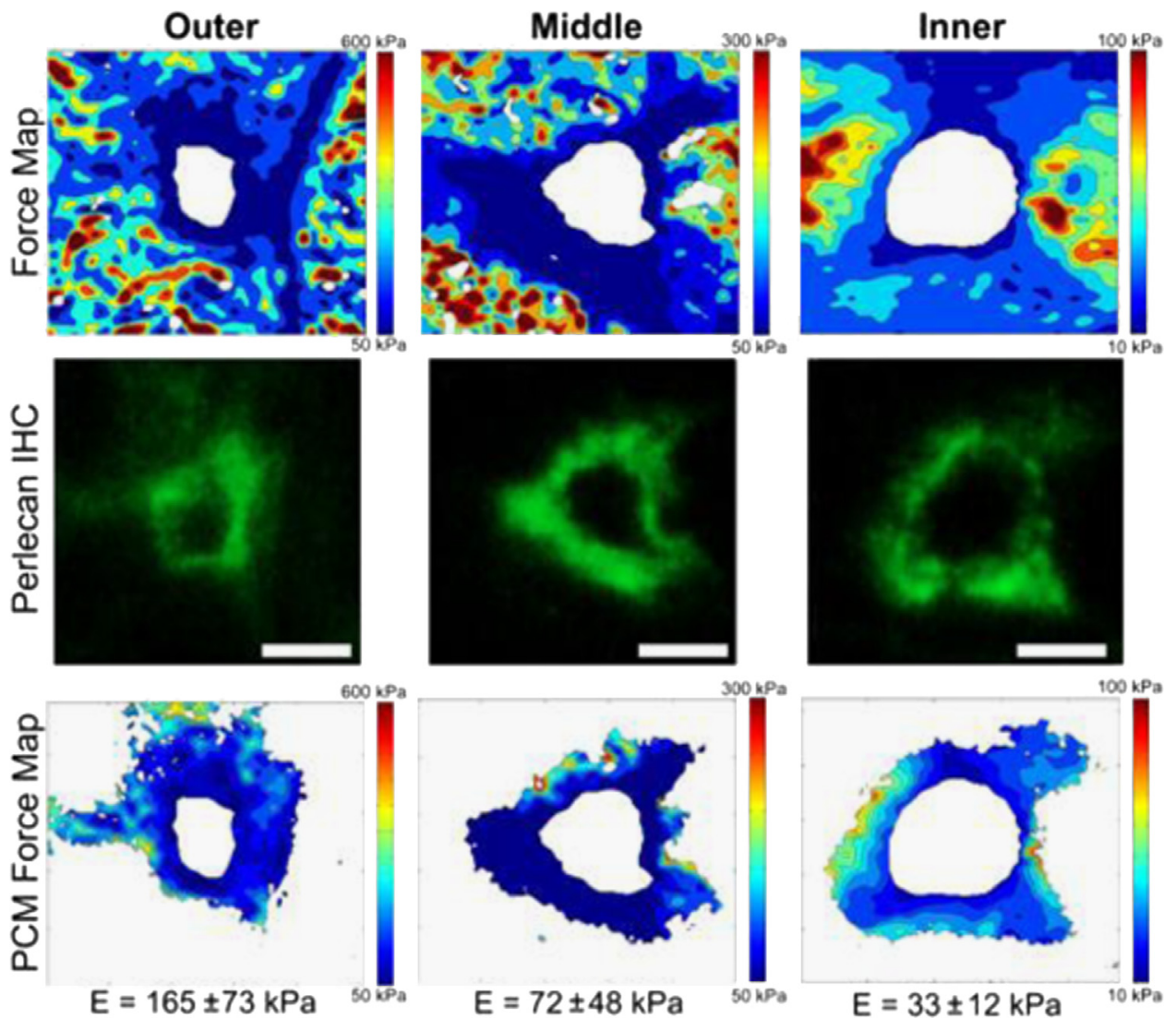

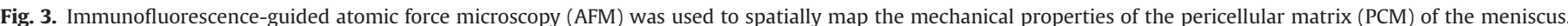

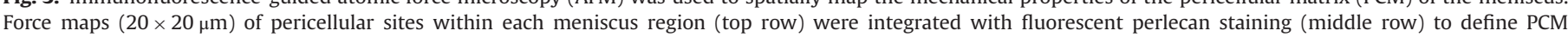

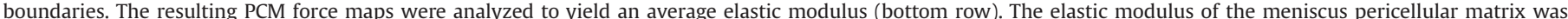

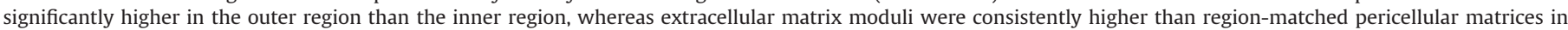
both outer and inner regions. Adapted from Sanchez-Adams et al. (2013) and Wilusz et al. (2014).

NO (Gupta et al., 2008) and enhanced aggrecan gene expression (Aufderheide and Athanasiou, 2006) but also increased the catabolic genes cyclooxygenase-2 (COX2) and a disintegrin and metalloproteinase with thrombospondin (ADAMTS)-5 (Zielinska et al., 2009). However, higher strain magnitudes of $20 \%$ induced a pathologic response characterized by the upregulation of matrix metalloproteinase (MMP)-1, MMP-3, MMP-13, ADAMTS-4, inducible nitric oxide synthase (NOS2), and interleukin- $1 \alpha$ (IL-1 $\alpha$ ) mRNA, and consequently resulted in increased NO release and the breakdown of proteoglycans
(Gupta et al., 2008; McHenry et al., 2006; Zielinska et al., 2009). On the other hand, the expression of type I collagen, tissue inhibitor of metalloproteinases (TIMP)-1, and transforming growth factor (TGF)- $\beta$ was not regulated by mechanical loading of meniscal explants between $0 \%$ and $20 \%$ dynamic compression (Zielinska et al., 2009).

In addition to determining the effects of physiologic strain on meniscal tissue explants, overloading models elucidate the response of the tissue to injurious loads. The application of $40 \%$ strain to immature bovine meniscal explants at increasing strain rates 
$(0.5 \% / \mathrm{s}, 5 \% / \mathrm{s}$, and $50 \% / \mathrm{s})$ induced biological but not physical or compositional changes in the meniscus tissue (Nishimuta and Levenston, 2012). Cell metabolism was lowest at day 1 following overloading for the two highest strain rates tested and cell lysis was correlated with loading rate and peak injury force. However, there was no macroscopic damage to the tissue and the sulfated glycosaminoglycan (sGAG) content of the tissue, sGAG release, and mechanical properties were unaffected. Overloading of inner zone meniscal explants with a single insult of $50 \%$ strain at $100 \%$ strain $/ \mathrm{s}$ caused large regions of cell death at the surface of the tissue, but surprisingly there was no gross damage to the tissue and downregulation of many catabolic and pro-inflammatory genes (Kisiday et al., 2010).

The loading configuration and history can also differentially regulate meniscal cell responses. For example, static compressive stress of $0.1 \mathrm{MPa}$ for $24 \mathrm{~h}$ downregulated types I and II collagen and decorin and increased MMP-1 gene expression, while dynamic stress suppressed the expression of decorin and type II collagen (Upton et al., 2003). On the other hand, oscillatory tension at $1 \mathrm{~Hz}$ and $10 \%$ displacement of immature bovine meniscal cells in 3D fibrin constructs decreased DNA content, sGAG content, and ${ }^{35} \mathrm{~S}$-sulfate incorporation (Vanderploeg et al., 2004). Over time in culture, the meniscal cells developed a stellate morphology and organized cytoskeletal filaments composed of F-actin, vimentin, and vinculin filaments; however, loading had no effects on the cytoskeletal morphology of the cells. Hydrostatic pressure can also regulate the metabolic activities of meniscal cells. The static application of $4 \mathrm{MPa}$ of hydrostatic pressure for $4 \mathrm{~h}$ to human meniscal cells in alginate beads resulted in the suppression of MMP-1 and MMP-13 mRNA levels (Suzuki et al., 2006). Conversely, cyclic hydrostatic pressure at $1 \mathrm{~Hz}$ resulted in the upregulation of mRNA transcripts for type I collagen, TIMP-1, and TIMP-2. The culture of rabbit meniscal explants increased catabolic gene expression, including mRNAs for MMP-1, MMP-3, TIMPs, NOS2, COX2, IL-1 $\beta$, and IL-6 (Natsu-Ume et al., 2005). However, the application of $1 \mathrm{MPa}$ cyclic hydrostatic pressure at $0.5 \mathrm{~Hz}$ for $4 \mathrm{~h}$ prevented these culture-induced increases in catabolic gene expression. These studies reveal that the response of the meniscus to mechanical loading is at least partially regulated at the transcriptional level (Upton et al., 2003) and that mechanical loading can maintain meniscal tissue homeostasis during culture (NatsuUme et al., 2005).

Few studies have explored the interaction of growth factors and mechanical loading on meniscal explants. TGF- $\beta 1$, insulin-like growth factor (IGF)-1, and platelet derived growth factor (PDGF)$\mathrm{AB}$ increased both protein and proteoglycan production by immature bovine meniscal explants (Imler et al., 2004). In the presence of these growth factors, $25-50 \%$ static compression for 4 days caused a suppression of matrix production equivalent to uncompressed controls, suggesting that the growth factors and mechanical stimulation may modulate meniscal metabolism through separate pathways. While TGF- $\beta$ is not regulated at the transcriptional level by 10-20\% dynamic compression (Zielinska et al., 2009), the combined treatment of meniscal explants with growth factors and dynamic compression has not yet been reported.

Joint injuries and arthritis affect both the biomechanical and the biochemical environment of the menisci. Following joint injury and in arthritic joints, the pro-inflammatory cytokine IL-1 is upregulated, with median synovial fluid concentrations rising to $109 \mathrm{pg} / \mathrm{mL}$ in mild osteoarthritic joints and $288 \mathrm{pg} / \mathrm{mL}$ in moderate osteoarthritic joints (McNulty et al., 2013). A number of studies have elucidated an interaction between pro-inflammatory pathways and mechanical signaling in meniscal explants. Dynamic compression of porcine meniscal explants at $0.1 \mathrm{MPa}$ and $0.5 \mathrm{~Hz}$ for $24 \mathrm{~h}$ increased NOS2 protein levels, NO production (Fink et al., 2001), protein and proteoglycan synthesis (Shin et al., 2003), and proteoglycan release. In addition, dynamic compression ranging from 0.0125 to $0.5 \mathrm{MPa}$ elevated prostaglandin $E_{2}$ (PGE2) and NO production in a stress magnitude dependent manner (Hennerbichler et al., 2007). NOS2 and NOS3 protein production was also increased by mechanical stimulation, and NO inhibitors suppressed the mechanically induced NO production (Hennerbichler et al., 2007). IL-1 blocked the compression induced increases in protein and proteoglycan synthesis; however, these increases were restored by the NOS2 inhibitor $1400 \mathrm{~W}$ (Shin et al., 2003). IL-1 also increased proteoglycan release and synergized with dynamic compression to further enhance release in a manner that was dependent on NO, specifically NOS2. Therefore, IL-1 modulates the effects of mechanical stress on meniscal tissue turnover via an NO dependent pathway (Shin et al., 2003). Pro-inflammatory and catabolic genes, such as IL-1 $1 \alpha$, MMP-1, MMP-3, and MMP-13, and SGAG release were increased by $20 \%$ dynamic compression at $1 \mathrm{~Hz}$ for $2 \mathrm{~h}$ in young porcine meniscal explants (Killian et al., 2011). However, in the presence of IL-1 receptor antagonist (IL-1ra), the pro-inflammatory and catabolic genes were suppressed, as compared to compression alone. Therefore, with altered joint loading due to injury or arthritis, the meniscus likely serves as a source of pro-inflammatory mediators.

\section{2D cell stretching studies}

The interplay between mechanical stimulation and inflammation is clearly established in explant model systems, however the specific downstream signaling pathways involved in meniscal mechanobiology can more easily be evaluated in 2D isolated meniscal cell cultures. For example, cyclic tensile strain has been shown to suppress the upregulation of NOS2, MMP-13, and TNF- $\alpha$ by IL- $1 \beta$ in a magnitude-dependent fashion, with greater than $90 \%$ suppression at $15 \%$ strain (Ferretti et al., 2006). Interestingly, these effects were frequency-dependent, such that higher frequencies more effectively suppressed IL-1 mediated catabolism. In addition, the anti-catabolic effects of mechanical loading were sustained up to $24 \mathrm{~h}$ after biomechanical stimulation, even in the continued presence of IL-1, suggesting the utility of biomechanical signals to block the catabolic effects of chronic inflammation following a joint injury or during arthritis.

While the mechanism of this response is not fully understood, cyclic tensile strain appears to antagonize IL- 1 signaling through pathways upstream of transcription (Agarwal et al., 2001). Meniscal cells constitutively expressed low levels of receptor activator of nuclear factor (NF- $\mathrm{kB}$ ) ligand (RANKL) and its cell surface receptor, RANK, but marked levels of the soluble neutralizing receptor osteoprotegerin (OPG) (Fig. 4A) (Deschner et al., 2006). IL-1 $\beta$ treatment caused the upregulation of RANK and RANKL but did not alter OPG expression. Cyclic tensile strain suppressed the IL-1 mediated upregulation of RANK and RANKL at both the mRNA (Fig. 4B) and protein levels (Fig. 4C and D) in a sustained, magnitude and frequency-dependent fashion. Therefore, mechanical stimulation utilizes the NF- $\mathrm{KB}$ signaling pathway to modulate the response to inflammation and regulate the transcription of pro-inflammatory mediators.

In other studies, TNF- $\alpha$ increased NO production and total protein synthesis, while suppressing proteoglycan synthesis in porcine meniscal cells from the inner zone (Fermor et al., 2004). The combination of $5 \%$ tensile strain at $0.5 \mathrm{~Hz}$ for $24 \mathrm{~h}$ and TNF- $\alpha$ suppressed the strain-dependent increase in proteoglycan synthesis, in a NOS2 independent fashion. This study provides evidence that inflammatory cytokines can modulate the response of meniscal cells to mechanical stimulation.

The distinct phenotypes of the cells in the inner and outer zones of the meniscal tissue likely play a role in their response to mechanical stimulation. In unloaded cells, mRNA levels for decorin and biglycan and total protein and NO production were similar 
A

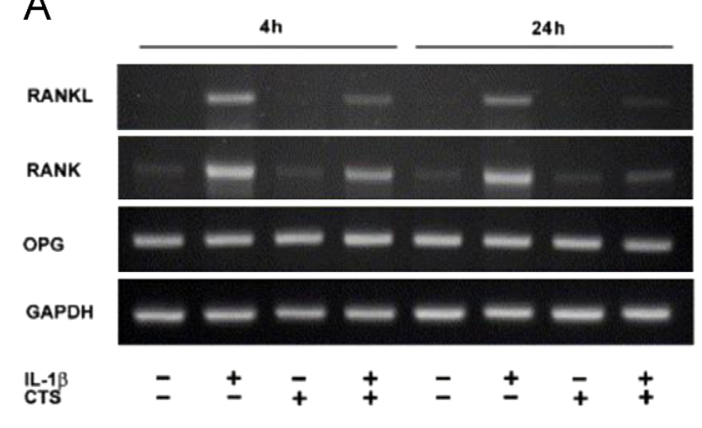

C

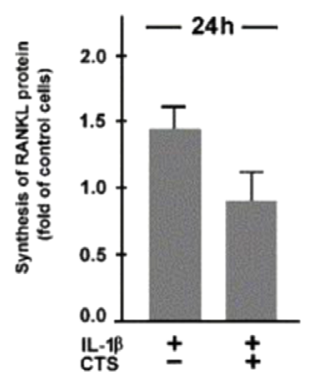

D

Control

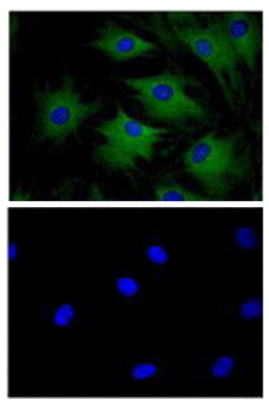

Negative Control
IL-1 $\beta$

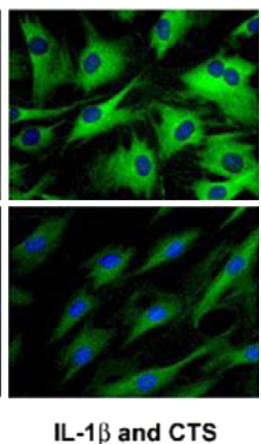

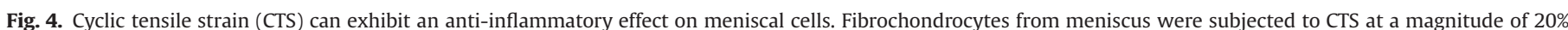

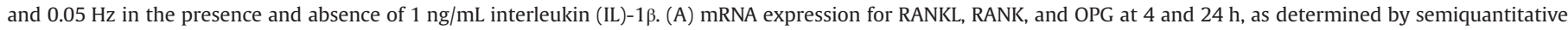

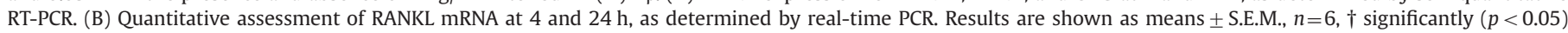

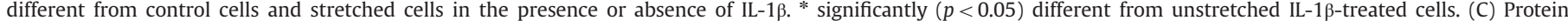

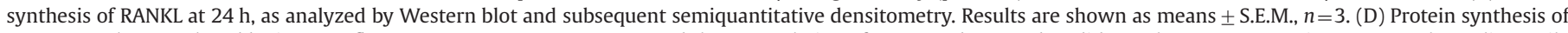

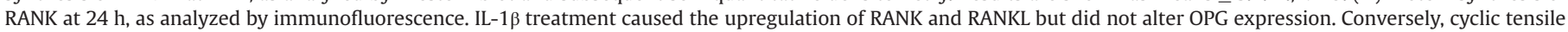
strain suppressed the IL-1 mediated upregulation of RANK and RANKL. Reprinted with permission from Deschner et al. (2006).

between isolated inner and outer zone meniscal cells (Upton et al., 2006b). In contrast, inner zone cells had higher mRNA levels of type II collagen, aggrecan, and NOS2 and higher rates of proteoglycan synthesis and outer zone cells had higher mRNA levels for type I collagen. The application of $5 \%$ biaxial tensile strain at $0.5 \mathrm{~Hz}$ increased total protein synthesis and NO production for both inner and outer zone cells. However, there were no strain-induced changes in proteoglycan synthesis or gene expression (Upton et al., 2006b). In contrast, type II collagen and SOX-9 were detectable in human osteoarthritic inner zone meniscal cells, but not in outer zone cells, and were upregulated at both mRNA and protein levels by $5 \%$ uniaxial cyclic tensile strain at $0.5 \mathrm{~Hz}$ (Kanazawa et al., 2012). In the inner zone cells, stretch stimulated nuclear translocation and phosphorylation of SOX-9 and increased the association of SOX-9 with its binding site on the Col2a1 enhancer in chromatin, suggesting a role for mechanical stimulation in the epigenetic regulation of type II collagen expression (Kanazawa et al., 2012). Uniaxial tensile strain also upregulated the expression of the multifunctional growth factor CYR61/CTGF/ NOV (CCN)-2 and type I collagen in inner zone meniscal cells but not outer zone cells (Furumatsu et al., 2012). Therefore, in addition to differences in the gene expression profiles of the inner and outer zones cells, meniscal cells from the two zones respond differently to mechanical stimulation.

\section{Mechanisms of mechanotransduction}

While the mechanobiologic response of meniscal cells has begun to be studied by a number of researchers, the mechanisms involved in mechanotransduction are still not well understood and remain to be elucidated. Many of the candidate mechanotransduction pathways examined in meniscal cells are based on those found in other cartilaginous cells, such as articular chondrocytes. For example, oscillatory fluid flow induced shear stresses ranging from 0 to $6.5 \mathrm{~Pa}$ caused an increase in intracellular $\mathrm{Ca}^{2+}$ and sGAG production in isolated rabbit meniscal cells (Eifler et al., 2006). The percentage of meniscal cells responding with a $\mathrm{Ca}^{2+}$ signal was positively correlated with the applied stress. Treatment of the mechanically stimulated cells with thapsigargin blocked both $\mathrm{Ca}^{2+}$ signaling and sGAG production (Eifler et al., 2006), suggesting that mechanically induced $\mathrm{Ca}^{2+}$ signaling may modulate meniscal extracellular matrix biosynthesis. However, the transporters and/or receptors that are responsible for sensing the mechanical load and transporting the $\mathrm{Ca}^{2+}$ into the meniscal cells have yet to be identified.

Recent advances have allowed the real time assessment of $\mathrm{Ca}^{2+}$ signaling during micromechanical loading on a confocal microscope (Han et al., 2014). Tensile deformation (0-9\%) was applied to juvenile bovine outer zone meniscal cells either in situ, in aligned poly ( $\varepsilon$-caprolactone) (PCL) scaffolds, or on silicone membranes (Han et al., 2014). Mechanical stimulation increased the amplitude of the peak $\mathrm{Ca}^{2+}$ signal in the meniscal cells in the context of the native tissue but not in meniscal cells on the scaffold or silicone membrane. In the native tissue, the percent of responding cells increased linearly from $0 \%$ to $9 \%$ strain, whereas in the scaffolds and on the silicone membrane the percent of responding cells increased linearly at a lower range of applied strains ( $<3 \%$ strain) (Han et al., 2014). In summary, this study showed that the meniscal cells in native tissue and tissue engineered constructs respond differently to mechanical stimulation and thus the $\mathrm{Ca}^{2+}$ signaling profile in 
native meniscal tissue provides benchmarks for mechanoregulation during the generation of tissue engineered constructs.

\section{Role of mechanical loading in tissue engineering and repair of the meniscus}

Our understanding of the influence of mechanical factors on meniscal metabolism can be exploited to promote meniscal regeneration and repair. Therefore, tissue engineering strategies, which involve the combination of cells, scaffolds, growth factors, and bioreactors, are being explored to regenerate new meniscal tissue for the replacement of injured and/or degenerated meniscal tissue (AufderHeide and Athanasiou, 2004; Guilak et al., 2014). Current work focuses on determining the optimal cell types, scaffolds, growth factors, type of mechanical stimulation, and loading regimes to generate tissue engineered meniscal constructs that reach the biomechanical benchmarks of native meniscal tissue (Setton et al., 1999). Perfusion culture has been utilized to help promote diffusion into tissue engineered constructs. An optimal flow rate of $40 \mathrm{~mL} / \mathrm{min}$ was determined for cell viability and extracellular matrix production, using polyethylene terephthalate scaffolds seeded with ovine fibrochondrocytes, as lower flow rates led to poor cell growth and higher rates of flow were destructive (Neves et al., 2002). However, oxygen deprivation in the center of the constructs was still problematic. Therefore, subsequent studies have utilized both perfusion and mechanical compression to generate tissue engineered meniscal constructs. Collagen meniscus implants seeded with human bone marrow stem cells (MSCs) showed increased procollagen types I and III peptide and construct mechanical properties with $10 \mathrm{~mL} / \mathrm{min}$ perfusion and $10 \%$ dynamic strain at $0.5 \mathrm{~Hz}$ (Petri et al., 2012). Perfusion combined with shorter bouts of $10 \%$ dynamic strain at $0.5 \mathrm{~Hz}$ also increased the equilibrium modulus 1.85 fold and increased type I procollagen and extracellular matrix deposition in porous polyurethane scaffolds seeded with human MSCs (Liu et al., 2012). In addition, cell viability, density, and proliferation were enhanced with perfusion and strain, as was the tensile modulus, which was increased two-fold to approximately $1 \mathrm{MPa}$ at 1 week. While dynamic compression and perfusion increased the mechanical properties of tissue engineered constructs, these scaffolds do not yet approach the tensile modulus of $\sim 100 \mathrm{MPa}$ and the equilibrium compressive modulus of $\sim 200 \mathrm{kPa}$ for native meniscal tissue (Setton et al., 1999).

Dynamic compressive loading of anatomically shaped scaffolds has also shown promise in the generation of tissue engineered meniscal constructs. Immature bovine meniscal cells were seeded into $2 \%$ alginate and crosslinked in meniscus shaped molds and then loaded by unconfined compression at $15 \%$ strain and $1 \mathrm{~Hz} 3$ times/week for up to 6 weeks using anatomically shaped loading platens (Ballyns and Bonassar, 2011). After only 2 weeks of dynamic compression, the extracellular matrix content was enhanced and the compressive modulus was approximately $70 \%$ of the native meniscal tissue. Interestingly, 2 weeks of loading followed by 4 weeks of static culture resulted in a more mature matrix, including increased collagen bundle formation, sGAG content, collagen content, and 4.3-fold increased compressive equilibrium modulus (Puetzer et al., 2012). The simultaneous application of dynamic compression at $10 \%$ strain and $1 \mathrm{~Hz}$ for $1 \mathrm{~h} /$ day and circumferential tension loading has also been assessed, using anatomically wedge shaped self-assembly meniscal constructs composed of young bovine articular chondrocytes and meniscal cells (Huey and Athanasiou, 2011). With early mechanical loading from days 10 to 14 , the compressive and tensile moduli were enhanced slightly and further increased 3 to 6 -fold by treatment with chondroitinase $A B C$ and TGF- $\beta 1$ in combination with mechanical stimulation. However, in each of these studies the tissue engineered construct properties are still less than the native mechanical properties.
In addition to the optimization of different loading regimes to promote meniscal tissue regeneration, various techniques have also been utilized to direct the deposition of extracellular matrix components within the scaffolds. Bacterial cellulose scaffolds that contain $500 \mu \mathrm{m}$ diameter microchannels promoted the alignment of 3 T6 mouse fibroblasts and also collagen fiber alignment within the scaffold (Martinez et al., 2012). The application of 5\% dynamic compression at $0.1 \mathrm{~Hz}$ enhanced collagen production on the scaffolds as well. Aligned and randomly organized electrospun PCL scaffolds have also been utilized to control cell morphology and matrix deposition in meniscus tissue engineered constructs (Nathan et al., 2011). The cell nuclei aligned with the predominant scaffold fiber orientation. In addition, the application of up to $10 \%$ tensile strain of aligned scaffolds further enhanced the orientation and elongation of cells (increased the nuclear aspect ratio) in the direction of fiber alignment or the nuclei reoriented in the direction of the applied load. Furthermore, actin was necessary for the loading-induced changes in the nuclear aspect ratio, while microtubules and intermediate filaments were not essential for this response. Interestingly human MSCs were more pliable and responsive to these biophysical cues than differentiated osteoarthritic meniscal cells, suggesting that biophysical methods can be utilized to promote tissue maturation with stem cells. However, the infiltration of cells throughout electrospun scaffolds is also challenging. Recently, the use of an orbital shaker at $1.2 \mathrm{~Hz}$ improved cellular infiltration of young bovine MSCs, increased collagen content, and the uniform distribution of collagen throughout the constructs but suppressed SGAG content, relative to free swelling conditions (Nerurkar et al., 2011). On the other hand 6 weeks of dynamic culture followed by 6 weeks of free swelling culture promoted cell infiltration, sGAG accumulation, and enhanced the stiffness of constructs. The preculture of MSCs on aligned electrospun PCL scaffolds for 6 weeks in free swelling conditions followed by $6 \%$ dynamic tensile strain at $1 \mathrm{~Hz}$ for $3 \mathrm{~h} /$ day for 4 weeks upregulated type I collagen, fibronectin, and lysyl oxidase mRNA levels (Baker et al., 2011). In addition, tensile loading enhanced collagen deposition and the tensile modulus was increased from $27 \mathrm{MPa}$ to $35 \mathrm{MPa}$ but there was no enhancement of proteoglycan content. These results suggest that is it possible to recapitulate the structure and biomechanical environment of the meniscus to start approaching the functional properties for tissue engineered menisci but further optimization is still necessary to determine the optimal loading regimes and scaffold design to reproduce the mechanical properties of the meniscus and also the extracellular matrix structure and composition for tissue regeneration.

In order to prevent the long-term development of osteoarthritis, ideally clinical therapies following a meniscal tear would preserve the meniscal tissue to promote repair and restoration of a functional meniscal tissue. However, the difficulty of integrating torn meniscal tissue continues to be a challenge for long-term efficacy of meniscus repair strategies (McNulty and Guilak, 2008; Riera et al., 2011). An in vitro meniscal repair model system, using cylindrical porcine meniscal explants that have a central core removed with a biopsy punch and reinserted immediately to simulate a full thickness meniscal tear have been utilized to assess strategies to promote integrative meniscal repair (McNulty et al., 2010; McNulty et al., 2007). Physiologic concentrations of IL-1 decreased meniscal cell proliferation, and increased MMP activity, S-GAG release and NO production, and suppressed the integrative shear strength of repair (McNulty et al., 2010, 2007; Riera et al., 2011). However, $1 \%, 10 \%$ and $26 \%$ dynamic strain at $1 \mathrm{~Hz}$ for $4 \mathrm{~h}$ /day for 14 days antagonized the IL- 1 inhibition of integrative meniscal repair (Fig. 5) and suppressed IL-1 mediated increases in MMP activity, S-GAG release, and NO production (McNulty et al., 2010). Interestingly, 26\% dynamic compression alone enhanced the integrative shear strength of repair. Therefore, joint loading 

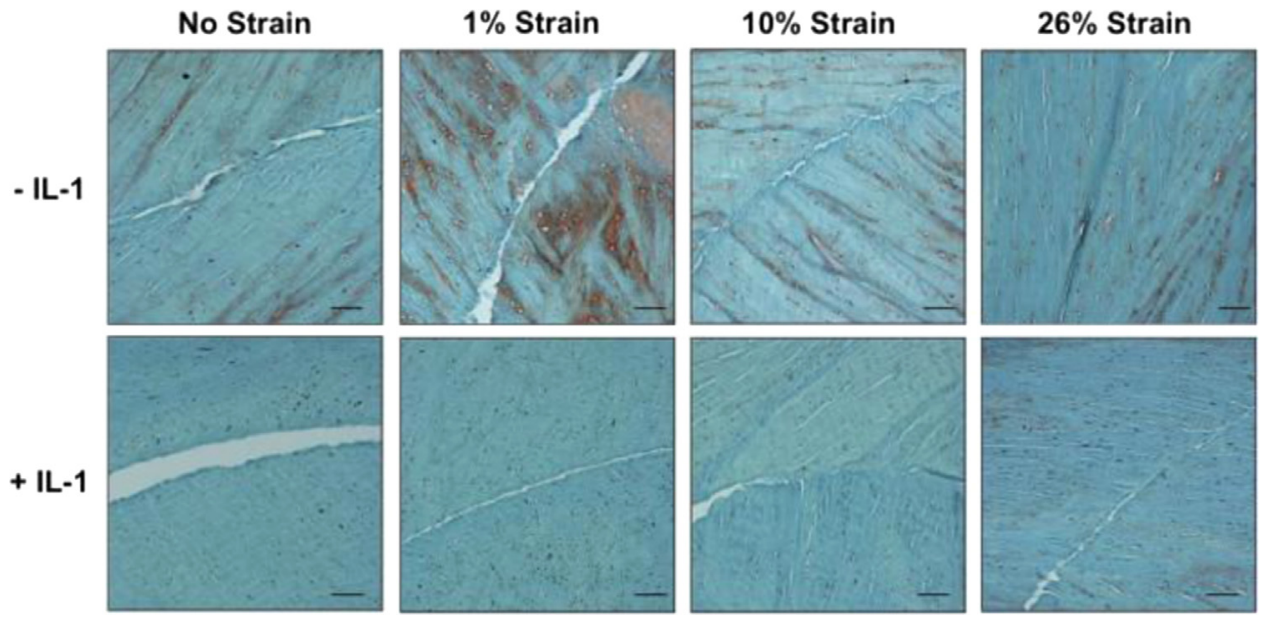

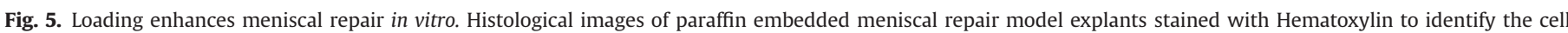

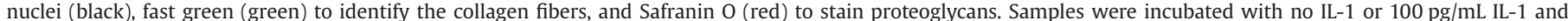

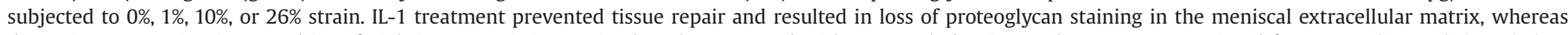

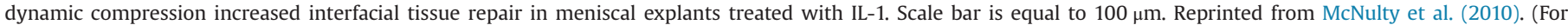
interpretation of the references to color in this figure legend, the reader is referred to the web version of this article.)

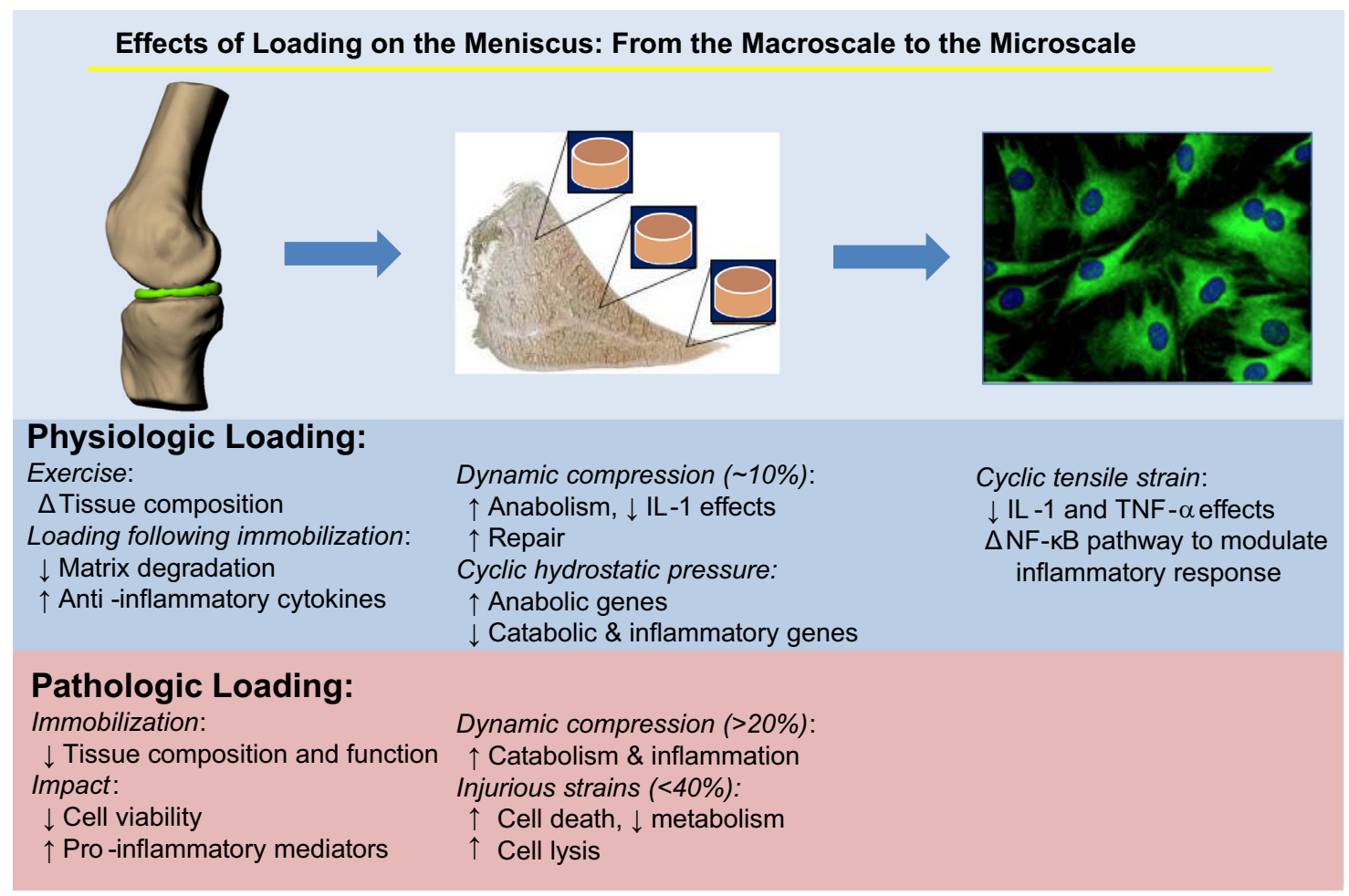

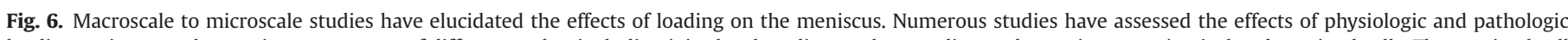

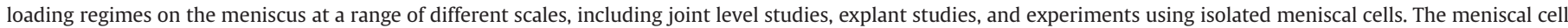
image is reprinted with permission from Deschner et al. (2006).

following a meniscal tear may be beneficial to promote integrative tissue repair.

\section{Conclusions}

In summary, these studies provide significant in vivo and in vitro evidence that mechanical factors play an important role in the health, degeneration, and regeneration of the meniscus (Fig. 6). It is evident that the process of mechanical signal transduction involves a complex sequence of mechanical and biochemical events. Through an array of experimental and theoretical studies, investigators have begun to directly measure the effects of joint loading on the meniscus, showing significant deformation and volume changes that occur under normal physiologic conditions. Using computational models and experimental pressure sensors, it is clear that the meniscus undergoes highly complex loading during the activities of daily living. Furthermore, theoretical and experimental models at the microscale level indicate that the cells in the meniscus are exposed to an environment of stress, strain, fluid pressure, fluid flow, and physicochemical factors that vary with time and site in the tissue. In 2D and 3D culture systems, these physical factors have been shown to have significant influences on meniscal cell responses, and single cell experiments have begun to 
provide new insights into the mechanisms by which mechanical and other biophysical signals are transduced. In this regard, a more thorough understanding of mechanobiologic responses of the meniscus will hopefully lead to new physical and/or pharmacologic therapies to prevent degeneration and enhance repair of the meniscus.

\section{Conflict of interest statement}

The authors have no conflicts of interest related to the content of the study.

\section{Acknowledgments}

We thank Dr. Louis DeFrate and Gangadhar Utturkar for assistance with manuscript preparation. This work was supported in part by the Collaborative Research Center of the AO Foundation (Davos, Switzerland), the Arthritis Foundation, and NIH Grants AR48182, AR48852, AG15768, AR50245, and AG46927.

\section{References}

Agarwal, S., Long, P., Gassner, R., Piesco, N.P., Buckley, M.J., 2001. Cyclic tensile strain suppresses catabolic effects of interleukin-1beta in fibrochondrocytes from the temporomandibular joint. Arthritis Rheumatol. 44, 608-617.

Anderson, D.R., Gershuni, D.H., Nakhostine, M., Danzig, L.A., 1993. The effects of non-weight-bearing and limited motion on the tensile properties of the meniscus. Arthroscopy 9, 440-445.

Andersson-Molina, H., Karlsson, H., Rockborn, P., 2002. Arthroscopic partial and total meniscectomy: a long-term follow-up study with matched controls. Arthroscopy 18, 183-189.

Arnoczky, S.P., Warren, R.F., 1983. The microvasculature of the meniscus and its response to injury. An experimental study in the dog. Am. J. Sports Med. 11, $131-141$

AufderHeide, A.C., Athanasiou, K.A., 2004. Mechanical stimulation toward tissue engineering of the knee meniscus. Ann. Biomed. Eng. 32, 1161-1174.

Aufderheide, A.C., Athanasiou, K.A., 2006. A direct compression stimulator for articular cartilage and meniscal explants. Ann. Biomed. Eng. 34, 1463-1474.

Baker, B.M., Shah, R.P., Huang, A.H., Mauck, R.L., 2011. Dynamic tensile loading improves the functional properties of mesenchymal stem cell-laden nanofiberbased fibrocartilage. Tissue Eng. Part A 17, 1445-1455.

Ballyns, J.J., Bonassar, L.J., 2011. Dynamic compressive loading of image-guided tissue engineered meniscal constructs. J. Biomech. 44, 509-516.

Bedi, A., Kelly, N.H., Baad, M., Fox, A.J., Brophy, R.H., Warren, R.F., Maher, S.A., 2010. Dynamic contact mechanics of the medial meniscus as a function of radial tear, repair, and partial meniscectomy. J. Bone Joint Surg. Am. 92, 1398-1408.

Bland-Sutton, J., 1897. Ligaments: Their Nature and Morphology. H.K. Lewis, London.

Bray, R.C., Smith, J.A., Eng, M.K., Leonard, C.A., Sutherland, C.A., Salo, P.T., 2001 Vascular response of the meniscus to injury: effects of immobilization. J Orthop. Res. 19, 384-390.

Burr, D.B., Frederickson, R.G., Pavlinch, C., Sickles, M., Burkart, S., 1984. Intracast muscle stimulation prevents bone and cartilage deterioration in castimmobilized rabbits. Clin. Orthop. Relat. Res. 189, 264-278.

Collier, S., Ghosh, P., 1995. Effects of transforming growth factor beta on proteoglycan synthesis by cell and explant cultures derived from the knee joint meniscus. Osteoarthr. Cartil. 3, 127-138.

Deschner, J., Wypasek, E., Ferretti, M., Rath, B., Anghelina, M., Agarwal, S., 2006. Regulation of RANKL by biomechanical loading in fibrochondrocytes of meniscus. J. Biomech. 39, 1796-1803.

Djurasovic, M., Aldridge, J.W., Grumbles, R., Rosenwasser, M.P., Howell, D., Ratcliffe, A., 1998. Knee joint immobilization decreases aggrecan gene expression in the meniscus. Am. J. Sports Med. 26, 460-466.

Dowdy, P.A., Miniaci, A., Arnoczky, S.P., Fowler, P.J., Boughner, D.R., 1995. The effect of cast immobilization on meniscal healing. An experimental study in the dog. Am. J. Sports Med. 23, 721-728.

Eifler, R.L., Blough, E.R., Dehlin, J.M., Haut Donahue, T.L., 2006. Oscillatory fluid flow regulates glycosaminoglycan production via an intracellular calcium pathway in meniscal cells. J. Orthop. Res. 24, 375-384.

Fairbank, T.J., 1948. Knee joint changes after meniscectomy. J. Bone Joint Surg. Br. 30B, 664-670.

Fermor, B., Jeffcoat, D., Hennerbichler, A., Pisetsky, D.S., Weinberg, J.B., Guilak, F. 2004. The effects of cyclic mechanical strain and tumor necrosis factor alpha on the response of cells of the meniscus. Osteoarthr. Cartil. 12, 956-962.

Ferretti, M., Madhavan, S., Deschner, J., Rath-Deschner, B., Wypasek, E., Agarwal, S. 2006. Dynamic biophysical strain modulates proinflammatory gene induction in meniscal fibrochondrocytes. Am. J. Physiol. Cell Physiol. 290, C1610-C1615.
Ferretti, M., Srinivasan, A., Deschner, J., Gassner, R., Baliko, F., Piesco, N., Salter, R., Agarwal, S., 2005. Anti-inflammatory effects of continuous passive motion on meniscal fibrocartilage. J. Orthop. Res. 23, 1165-1171.

Fink, C., Fermor, B., Weinberg, J.B., Pisetsky, D.S., Misukonis, M.A., Guilak, F., 2001. The effect of dynamic mechanical compression on nitric oxide production in the meniscus. Osteoarthr. Cartil. 9, 481-487.

Fithian, D.C., Kelly, M.A., Mow, V.C., 1990. Material properties and structurefunction relationships in the menisci. Clin. Orthop. Relat. Res. 252, 19-31.

Freutel, M., Seitz, A.M., Galbusera, F., Bornstedt, A., Rasche, V., Knothe Tate, M.L., Ignatius, A., Durselen, L., 2014. Medial meniscal displacement and strain in three dimensions under compressive loads: MR assessment. J. Magn. Reson. Imaging 40, 1181-1188.

Furumatsu, T., Kanazawa, T., Miyake, Y., Kubota, S., Takigawa, M., Ozaki, T., 2012. Mechanical stretch increases Smad3-dependent CCN2 expression in inner meniscus cells. J. Orthop. Res. 30, 1738-1745.

Guilak, F., Butler, D.L., Goldstein, S.A., Baaijens, F.P., 2014. Biomechanics and mechanobiology in functional tissue engineering. J. Biomech. 47, 1933-1940.

Guilak, F., Mow, V.C., 2000. The mechanical environment of the chondrocyte: a biphasic finite element model of cell-matrix interactions in articular cartilage. J. Biomech. 33, 1663-1673.

Gupta, T., Haut Donahue, T.L., 2006. Role of cell location and morphology in the mechanical environment around meniscal cells. Acta Biomater. 2, 483-492.

Gupta, T., Zielinska, B., McHenry, J., Kadmiel, M., Haut Donahue, T.L., 2008. IL-1 and iNOS gene expression and NO synthesis in the superior region of meniscal explants are dependent on the magnitude of compressive strains. Osteoarthr. Cartil. 16, 1213-1219.

Hall, M., Wrigley, T.V., Metcalf, B.R., Cicuttini, F.M., Wang, Y., Hinman, R.S., Dempsey, A.R., Mills, P.M., Lloyd, D.G., Bennell, K.L., 2014. Do moments and strength predict cartilage changes following partial meniscectomy? Med. Sci. Sports Exerc..

Halonen, K.S., Mononen, M.E., Jurvelin, J.S., Toyras, J., Salo, J., Korhonen, R.K., 2014. Deformation of articular cartilage during static loading of a knee jointexperimental and finite element analysis. J. Biomech. 47, 2467-2474.

Han, W.M., Heo, S.J., Driscoll, T.P., Boggs, M.E., Duncan, R.L., Mauck, R.L., Elliott, D.M., 2014. Impact of cellular microenvironment and mechanical perturbation on calcium signalling in meniscus fibrochondrocytes. Eur. Cell Mater. 27, 321-331.

Han, W.M., Heo, S.J., Driscoll, T.P., Smith, L.J., Mauck, R.L., Elliott, D.M., 2013. Macroto microscale strain transfer in fibrous tissues is heterogeneous and tissuespecific. Biophys. J. 105, 807-817.

Hellio Le Graverand, M.P., Ou, Y., Schield-Yee, T., Barclay, L., Hart, D., Natsume, T., Rattner, J.B., 2001. The cells of the rabbit meniscus: their arrangement, interrelationship, morphological variations and cytoarchitecture. J. Anat. 198, $525-535$.

Hennerbichler, A., Fermor, B., Hennerbichler, D., Weinberg, J.B., Guilak, F., 2007. Regional differences in prostaglandin E2 and nitric oxide production in the knee meniscus in response to dynamic compression. Biochem. Biophys. Res. Commun. 358, 1047-1053.

Hoser, C., Fink, C., Brown, C., Reichkendler, M., Hackl, W., Bartlett, J., 2001. Longterm results of arthroscopic partial lateral meniscectomy in knees without associated damage. J. Bone Joint Surg. Br. 83-B, 513-516.

Huey, D.J., Athanasiou, K.A., 2011. Tension-compression loading with chemical stimulation results in additive increases to functional properties of anatomic meniscal constructs. PLoS One 6, e27857.

Imler, S.M., Doshi, A.N., Levenston, M.E., 2004. Combined effects of growth factors and static mechanical compression on meniscus explant biosynthesis. Osteoarthr. Cartil. 12, 736-744.

Kanazawa, T., Furumatsu, T., Hachioji, M., Oohashi, T., Ninomiya, Y., Ozaki, T., 2012. Mechanical stretch enhances COL2A1 expression on chromatin by inducing SOX9 nuclear translocalization in inner meniscus cells. J. Orthop. Res. 30, 468-474.

Kawahara, Y., Uetani, M., Fuchi, K., Eguchi, H., Hayashi, K., 1999. MR assessment of movement and morphologic change in the menisci during knee flexion. Acta Radiol. 40, 610-614.

Kessler, M.A., Glaser, C., Tittel, S., Reiser, M., Imhoff, A.B., 2006. Volume changes in the menisci and articular cartilage of runners: an in vivo investigation based on 3-D magnetic resonance imaging. Am. J. Sports Med. 34, 832-836.

Killian, M.L., Haut, R.C., Haut Donahue, T.L., 2014. Acute cell viability and nitric oxide release in lateral menisci following closed-joint knee injury in a lapine model of post-traumatic osteoarthritis. BMC Musculoskelet Disord. 15, 297.

Killian, M.L., Zielinska, B., Gupta, T., Haut Donahue, T.L., 2011. In vitro inhibition of compression-induced catabolic gene expression in meniscal explants following treatment with IL-1 receptor antagonist. J. Orthop. Sci. 16, 212-220.

Kisiday, J.D., Vanderploeg, E.J., McIlwraith, C.W., Grodzinsky, A.J., Frisbie, D.D., 2010. Mechanical injury of explants from the articulating surface of the inner meniscus. Arch. Biochem. Biophys. 494, 138-144.

Klein, L., Heiple, K.G., Torzilli, P.A., Goldberg, V.M., Burstein, A.H., 1989. Prevention of ligament and meniscus atrophy by active joint motion in a non-weightbearing model. J. Orthop. Res. 7, 80-85.

Klein, L., Player, J.S., Heiple, K.G., Bahniuk, E., Goldberg, V.M., 1982. Isotopic evidence for resorption of soft tissues and bone in immobilized dogs. J. Bone Joint Surg. Am. 64, 225-230.

Lai, J.H., Levenston, M.E., 2010. Meniscus and cartilage exhibit distinct intra-tissue strain distributions under unconfined compression. Osteoarthr. Cartil. 18, 1291-1299.

LeRoux, M.A., Setton, L.A., 2002. Experimental and biphasic FEM determinations of the material properties and hydraulic permeability of the meniscus in tension. J. Biomech. Eng. 124, 315-321. 
Liu, C., Abedian, R., Meister, R., Haasper, C., Hurschler, C., Krettek, C., von Lewinski, G., Jagodzinski, M., 2012. Influence of perfusion and compression on the proliferation and differentiation of bone mesenchymal stromal cells seeded on polyurethane scaffolds. Biomaterials 33, 1052-1064.

Makris, E.A., Hadidi, P., Athanasiou, K.A., 2011. The knee meniscus: structurefunction, pathophysiology, current repair techniques, and prospects for regeneration. Biomaterials 32, 7411-7431.

Martinez, H., Brackmann, C., Enejder, A., Gatenholm, P., 2012. Mechanical stimulation of fibroblasts in micro-channeled bacterial cellulose scaffolds enhances production of oriented collagen fibers. J. Biomed. Mater. Res. A 100, 948-957.

McDevitt, C.A., Li, H., Zaramo, C., Prajapati, R., 2001. The isolation of a cellpericellular matrix complex from meniscus fibrocartilage: the fibrochondron. Transactions of the Orthopaedic Research Society, Poster 0384.

McDevitt, C.A., Webber, R.J., 1990. The ultrastructure and biochemistry of meniscal cartilage. Clin. Orthop. Relat. Res. 252, 8-18.

McHenry, J.A., Zielinska, B., Donahue, T.L., 2006. Proteoglycan breakdown of meniscal explants following dynamic compression using a novel bioreactor. Ann. Biomed. Eng. 34, 1758-1766.

McNulty, A.L., Estes, B.T., Wilusz, R.E., Weinberg, J.B., Guilak, F., 2010. Dynamic loading enhances integrative meniscal repair in the presence of interleukin-1. Osteoarthr. Cartil. 18, 830-838.

McNulty, A.L., Guilak, F., 2008. Integrative repair of the meniscus: lessons from in vitro studies. Biorheology 45, 487-500.

McNulty, A.L., Moutos, F.T., Weinberg, J.B., Guilak, F., 2007. Enhanced integrative repair of the porcine meniscus in vitro by inhibition of interleukin-1 or tumor necrosis factor alpha. Arthritis Rheum. 56, 3033-3042.

McNulty, A.L., Rothfusz, N.E., Leddy, H.A., Guilak, F., 2013. Synovial fluid concentrations and relative potency of interleukin-1 alpha and beta in cartilage and meniscus degradation. J. Orthop. Res. 31, 1039-1045.

Meakin, J.R., Shrive, N.G., Frank, C.B., Hart, D.A., 2003. Finite element analysis of the meniscus: the influence of geometry and material properties on its behaviour. Knee 10, 33-41.

Mikic, B., Johnson, T.L., Chhabra, A.B., Schalet, B.J., Wong, M., Hunziker, E.B., 2000. Differential effects of embryonic immobilization on the development of fibrocartilaginous skeletal elements. J. Rehabil. Res. Dev. 37, 127-133.

Nathan, A.S., Baker, B.M., Nerurkar, N.L., Mauck, R.L., 2011. Mechano-topographic modulation of stem cell nuclear shape on nanofibrous scaffolds. Acta Biomater. 7, 57-66.

Natsu-Ume, T., Majima, T., Reno, C., Shrive, N.G., Frank, C.B., Hart, D.A., 2005. Menisci of the rabbit knee require mechanical loading to maintain homeostasis: cyclic hydrostatic compression in vitro prevents derepression of catabolic genes. J. Orthop. Sci. 10, 396-405.

Nerurkar, N.L., Sen, S., Baker, B.M., Elliott, D.M., Mauck, R.L., 2011. Dynamic culture enhances stem cell infiltration and modulates extracellular matrix production on aligned electrospun nanofibrous scaffolds. Acta Biomater. 7, 485-491.

Neves, A.A., Medcalf, N., Brindle, K.M., 2002. Tissue engineering of meniscal cartilage using perfusion culture. Ann. NY Acad. Sci. 961, 352-355.

Nishimuta, J.F., Levenston, M.E., 2012. Response of cartilage and meniscus tissue explants to in vitro compressive overload. Osteoarthr. Cartil. 20, 422-429.

Ochi, M., Kanda, T., Sumen, Y., Ikuta, Y., 1997. Changes in the permeability and histologic findings of rabbit menisci after immobilization. Clin. Orthop. Relat. Res., 305-315.

Pangborn, C.A., Athanasiou, K.A., 2005. Effects of growth factors on meniscal fibrochondrocytes. Tissue Eng. 11, 1141-1148.

Pedrini-Mille, A., Pedrini, V.A., Maynard, J.A., Vailas, A.C., 1988. Response of immature chicken meniscus to strenuous exercise: biochemical studies of proteoglycan and collagen. J. Orthop. Res. 6, 196-204.

Petri, M., Ufer, K., Toma, I., Becher, C., Liodakis, E., Brand, S., Haas, P., Liu, C., Richter, B., Haasper, C., von Lewinski, G., Jagodzinski, M., 2012. Effects of perfusion and cyclic compression on in vitro tissue engineered meniscus implants. Knee Surg. Sports Traumatol. Arthrosc. 20, 223-231.

Puetzer, J.L., Ballyns, J.J., Bonassar, L.J., 2012. The effect of the duration of mechanical stimulation and post-stimulation culture on the structure and properties of dynamically compressed tissue-engineered menisci. Tissue Eng. Part A 18, 1365-1375.

Riera, K.M., Rothfusz, N.E., Wilusz, R.E., Weinberg, J.B., Guilak, F., McNulty, A.L., 2011. Interleukin-1, tumor necrosis factor-alpha, and transforming growth factor-beta 1 and integrative meniscal repair: influences on meniscal cell proliferation and migration. Arthritis Res. Ther. 13, R187.
Roos, E.M., Ostenberg, A., Roos, H., Ekdahl, C., Lohmander, L.S., 2001. Long-term outcome of meniscectomy: symptoms, function, and performance tests in patients with or without radiographic osteoarthritis compared to matched controls. Osteoarthr. Cartil. 9, 316-324.

Sanchez-Adams, J., Athanasiou, K.A., 2012. Biomechanics of meniscus cells: regional variation and comparison to articular chondrocytes and ligament cells. Biomech. Model Mechanobiol. 11, 1047-1056.

Sanchez-Adams, J., Wilusz, R.E., Guilak, F., 2013. Atomic force microscopy reveals regional variations in the micromechanical properties of the pericellular and extracellular matrices of the meniscus. J. Orthop. Res. 31, 1218-1225.

Scott, G.A., Jolly, B.L., Henning, C.E., 1986. Combined posterior incision and arthroscopic intra-articular repair of the meniscus. An examination of factors affecting healing. J. Bone Joint Surg. Am. 68, 847-861.

Setton, L.A., Guilak, F., Hsu, E.W., Vail, T.P., 1999. Biomechanical factors in tissue engineered meniscal repair. Clin. Orthop. Relat. Res. 367, S254-S272.

Shin, S.J., Fermor, B., Weinberg, J.B., Pisetsky, D.S., Guilak, F., 2003. Regulation of matrix turnover in meniscal explants: role of mechanical stress, interleukin-1, and nitric oxide. J. Appl. Physiol. 95, 308-313.

Spilker, R.L., Donzelli, P.S., Mow, V.C., 1992. A transversely isotropic biphasic finite element model of the meniscus. J. Biomech. 25, 1027-1045.

Stehling, C., Luke, A., Stahl, R., Baum, T., Joseph, G., Pan, J., Link, T.M., 2011. Meniscal T1rho and T2 measured with 3.0T MRI increases directly after running a marathon. Skelet. Radiol. 40, 725-735.

Suzuki, T., Toyoda, T., Suzuki, H., Hisamori, N., Matsumoto, H., Toyama, Y., 2006 Hydrostatic pressure modulates mRNA expressions for matrix proteins in human meniscal cells. Biorheology 43, 611-622.

Tienen, T.G., Buma, P., Scholten, J.G., van Kampen, A., Veth, R.P., Verdonschot, N. 2005. Displacement of the medial meniscus within the passive motion characteristics of the human knee joint: an RSA study in human cadaver knees. Knee Surg. Sports Traumatol. Arthrosc. 13, 287-292.

Upton, M.L., Chen, J., Guilak, F., Setton, L.A., 2003. Differential effects of static and dynamic compression on meniscal cell gene expression. J. Orthop. Res. 21, 963-969.

Upton, M.L., Gilchrist, C.L., Guilak, F., Setton, L.A., 2008. Transfer of macroscale tissue strain to microscale cell regions in the deformed meniscus. Biophys. J. 95, 2116-2124.

Upton, M.L., Guilak, F., Laursen, T.A., Setton, L.A., 2006a. Finite element modeling predictions of region-specific cell-matrix mechanics in the meniscus. Biomech. Model Mechanobiol. 5, 140-149.

Upton, M.L., Hennerbichler, A., Fermor, B., Guilak, F., Weinberg, J.B., Setton, L.A. 2006b. Biaxial strain effects on cells from the inner and outer regions of the meniscus. Connect. Tissue Res. 47, 207-214.

Vailas, A.C., Zernicke, R.F., Matsuda, J., Curwin, S., Durivage, J., 1986. Adaptation of rat knee meniscus to prolonged exercise. J. Appl. Physiol. 60, 1031-1034.

Vanderploeg, E.J., Imler, S.M., Brodkin, K.R., Garcia, A.J., Levenston, M.E., 2004. Oscillatory tension differentially modulates matrix metabolism and cytoskeletal organization in chondrocytes and fibrochondrocytes. J. Biomech. 37, 1941-1952.

Vedi, V., Williams, A., Tennant, S.J., Spouse, E., Hunt, D.M., Gedroyc, W.M., 1999. Meniscal movement. An in-vivo study using dynamic MRI. J. Bone Joint Surg. Br. 81, 37-41.

Verdonk, P.C., Forsyth, R.G., Wang, J., Almqvist, K.F., Verdonk, R., Veys, E.M. Verbruggen, G., 2005. Characterisation of human knee meniscus cell phenotype. Osteoarthr. Cartil. 13, 548-560.

Videman, T., Eronen, I., Friman, C., Langenskiold, A., 1979. Glycosaminoglycan metabolism of the medial meniscus, the medial collateral ligament and the hip joint capsule in experimental osteoarthritis caused by immobilization of the rabbit knee. Acta Orthop. Scand. 50, 465-470.

Walker, P.S., Erkman, M.J., 1975. The role of the menisci in force transmission across the knee. Clin. Orthop. Relat. Res., 184-192.

Wilusz, R.E., Sanchez-Adams, J., Guilak, F., 2014. The structure and function of the pericellular matrix of articular cartilage. Matrix Biol. 39C, 25-32.

Yao, J., Snibbe, J., Maloney, M., Lerner, A.L., 2006. Stresses and strains in the medial meniscus of an ACL deficient knee under anterior loading: a finite element analysis with image-based experimental validation. J. Biomech. Eng. 128, 135-141.

Zielinska, B., Killian, M., Kadmiel, M., Nelsen, M., Haut Donahue, T.L., 2009. Meniscal tissue explants response depends on level of dynamic compressive strain. Osteoarthr. Cartil. 17, 754-760. 